\title{
OS EFEITOS DA GESTÃO DA QUALIDADE E DA GESTÃO AMBIENTAL SOBRE A VANTAGEM COMPETITIVA: UM ESTUDO DE MÚLTIPLOS CASOS NA REDE HOTELEIRA DE PIPA/RN
}

\author{
THE EFFECTS OF QUALITY MANAGEMENT AND ENVIRONMENTAL \\ MANAGEMENT ON THE COMPETITIVE ADVANTAGE: A MULTIPLE CASE \\ STUDY IN THE HOTEL CHAIN IN PIPA / RN
}

\section{LOS EFECTOS DE LA GESTIÓN DE LA CALIDAD Y LA GESTIÓN AMBIENTAL SOBRE LA VENTAJA COMPETITIVA: UN ESTUDIO DE MÚLTIPLOS CASOS EN LA RED HOTELERA DE PIPA / RN}

\author{
Priscilla Correia Pereira ${ }^{1}$ \\ Leilianne M. T. Silva Barreto ${ }^{2}$ \\ Pablo Flôres Limberger ${ }^{3}$ \\ Luiz Mendes Filho ${ }^{4}$
}

\begin{abstract}
RESUMO
Com a mudança comportamental dos consumidores, que passaram a ser sensíveis às questões ambientais a partir da globalização, surge por consequência uma segmentação no mercado de pessoas que buscam empresas que adotam ferramentas e gestão para minimizar os impactos causados à natureza na produção e prestação de produtos e serviços ao mesmo tempo em que oferece estes com qualidade. Percebendo esta problemática, este artigo busca realizar uma análise sobre os impactos da gestão da qualidade e da gestão ambiental na competitividade na rede hoteleira de Pipa -Rio Grande do Norte, Brasil. A pesquisa tem uma abordagem de natureza qualitativa, exploratória, descritiva que utiliza um estudo de múltiplos casos com as três melhores pousadas avaliadas pelo usuário através do TripAdvisor. A coleta foi realizada com a utilização de roteiro de entrevista adaptado de modelo proposto por Molina-Azorín et al (2015). Os resultados indicam que a gestão da qualidade e a gestão ambiental permitem a melhoria da vantagem competitiva em termos de diferenciação. Além disso, a pousada que implementa programa de qualidade encontra menos obstáculos na implementação da gestão ambiental.
\end{abstract}

Palavras-chave: Hotelaria. Competitividade. Gestão da Qualidade. Gestão Ambiental. Pipa.

\begin{abstract}
With the behavioral change of consumers, who have become sensitive to environmental issues from globalization, there is a consequent segmentation in the market of people seeking companies that adopt tools and management to minimize the impacts caused to nature in the production and delivery of products and services while offering these with quality. Realizing this problem, this article seeks to perform an analysis on the impacts of quality management and environmental management on competitiveness in the hotel chain of Pipa-Rio Grande do Norte, Brazil. The research has a qualitative, exploratory, descriptive approach that uses a multiple case study with the three best inns evaluated by the user through TripAdvisor. The collection was carried out using an interview script adapted from a model proposed by Molina-Azorín et al (2015). The results indicate that quality management and environmental management allow the improvement of the competitive advantage in terms of differentiation. In addition, the inn that implements a quality program encounters fewer obstacles in the implementation of environmental management.
\end{abstract}

Keywords: Hotel, Competitiveness. Quality management. Environmental management. Pipa.

\section{RESUMEN}

\footnotetext{
${ }^{1}$ Bacharel em Turismo na Universidade Federal do Rio Grande do Norte (UFRN). E-mail: priscilla pereira21@ @otmail.com

${ }^{2}$ Profa. Doutora da Pós-Graduação em Turismo e do curso de Turismo da UFRN. E-mail: leiliannebarreto@ @otmail.com

${ }^{3}$ Professor e pesquisador no programa de mestrado e doutorado em turismo e hotelaria da Universidade do Vale do Itajaí e Doutor em turismo e hotelaria pela UNIVALI. E-mail: pablofl@univali.br

${ }^{4}$ Professor Doutor da Pós-Graduação em Turismo e do curso de Turismo da UFRN. E-mail: 1uiz.mendesfilho@gmail.com
} 
Con el cambio comportamental de los consumidores, que pasaron a ser sensibles a las cuestiones ambientales a partir de la globalización, surge por consecuencia una segmentación en el mercado de personas que buscan empresas que adoptan herramientas y gestión para minimizar los impactos causados a la naturaleza en la producción y prestación de productos y servicios al mismo tiempo que ofrece estos con calidad. En este artículo se busca realizar un análisis sobre los impactos de la gestión de la calidad y de la gestión ambiental en la competitividad en la red hotelera de Pipa -Rio Grande do Norte, Brasil.. La investigación tiene un enfoque de naturaleza cualitativa, exploratoria, descriptiva que utiliza un estudio de múltiples casos con las tres mejores posadas evaluadas por el usuario a través de TripAdvisor. Para la recolección de datos se realizó con la utilización de un itinerario de entrevista adaptado de modelo propuesto por Molina-Azorín et al (2015). Los resultados indican que la gestión de la calidad y la gestión ambiental permiten mejorar la ventaja competitiva en términos de diferenciación. Además, la posada que implementa programa de calidad encuentra menos obstáculos en la implementación de la gestión ambiental..

Palabras clave Hostelería. Competitividad. Gestión de la Calidad. Gestión ambiental. Pipa.

\section{INTRODUÇÃ̃O}

O mercado turístico tem como principal característica a venda de serviços, produtos intangíveis, não estocáveis. Por isso, é importante trabalhar com processos de melhoria contínua e estar sempre se adequando às exigências do mercado consumidor. A qualidade é um fator chave para as empresas se diferenciarem, especialmente em setores altamente competitivos como a hotelaria (PÉREZ; ARBELO; GÓMEZ, 2017).

Com a globalização, as empresas passaram a ser mais exigidas por parte dos consumidores. Os clientes recebem ofertas diversas e são cercados de variadas opções, com isso se tornaram mais rigorosos na escolha dos produtos/serviços que antes. Diante desse cenário mercadológico os clientes devem ser o principal foco das empresas, e quando se trata de serviços, a análise da satisfação dos clientes passa a ser mais difícil pela diversificação da percepção de cada. Assim, a qualidade na oferta do produto intangível passa ser vista como arma competitiva.

Diante disto, as empresas optam por uma produção eficiente que possa atender a demanda destes consumidores, e isto pode ser considerado um grande desafio moderno, pois os consumidores possuem facilidade de acesso a produtos, bens e serviços que atendam suas necessidades de maneira adequada. A partir desta percepção, é possível compreender que o desenvolvimento de um mercado exigente altera desde o produto final como a gestão para o seu desenvolvimento. Percebendo isto, Carpinetti (2010) acredita que para manter a empresa competitiva no mercado e conquistar clientes, é necessário que ela possa atender de forma satisfatória aos clientes quanto aos serviços e produtos ofertados. 
Portanto, a partir destas percepções sobre a importância da gestão da qualidade é possível compreender que a empresa precisa não apenas oferecer um produto/serviço para uma demanda específica, mas sim, buscar estar sempre se superando e desenvolvendo novos e melhores produtos que atendam de forma satisfatória clientes que agora são mais exigentes. No entanto, esta estratégia de adoção da gestão da qualidade não aconteceu no mercado de forma abrupta, foi um processo de mudança que teve suas variações de acordo com o setor que encontrou como variável propulsora o mercado consumidor (PALADINI, 2010).

Apesar deste tipo de gestão ter sido inserido de forma gradativa em alguns setores, impactos ambientais foram ocasionados pela excessiva oferta de bens e serviços em um curto espaço de tempo, principalmente na área do Turismo a qual possui apoio dos poderes públicos municipais, estaduais, e federais e recebem investimentos fiscais destes.

A partir disto, e da percepção destes impactos ambientais pelos consumidores, o mercado vem se segmentando e existem consumidores preocupados com a sustentabilidade, que optam por empreendimentos que adotam ferramentas de gestão ambiental na produção de produtos/ serviços. Por isso, é importante entender que existe segmentos que valorizam este tipo de gestão e que se analisado e desenvolvido serviços que atendam esta demanda, o empreendimento estará se diferenciando e conseguindo se destacar em uma vantagem competitiva.

Percebendo a importância deste assunto e dos poucos trabalhos em Pipa-RN e recentes na área (MOLINA-AZORÍN et al., 2015; PRAJOGO, 2007) que tenham resultados conclusivos sobre a influência da gestão da qualidade na competitividade, bem como a gestão ambiental na competitividade, que se destaca a necessidade deste trabalho, em estudar os impactos destes dois tipos de gestão na hotelaria.

Para efeito desta pesquisa, limitou-se Praia de Pipa localizada no município de Tibau do Sul, uma vez que este, se destacou como um destino reconhecido tanto no âmbito nacional quanto internacional, atraindo diversos investimentos e acolhendo pessoas de diversas nacionalidades (VIDAL, 2010). O município disponibiliza mais de 5.000 leitos distribuídos entre hotéis, pousadas e albergues com capacidade para receber 5.174 hóspedes por dia, sendo 85\% destes localizados na Praia de Pipa (IBGE, 2011). Por isso, faz-se necessário estudos que auxiliem os empreendimentos localizados nesta área para que estes tenham impactos positivos sob essa demanda crescente. 
Nesse contexto, o presente trabalho se propõe a analisar os impactos da gestão da qualidade e da gestão ambiental na competitividade da rede hoteleira de Pipa/RN.

\section{GESTÃO DA QUALIDADE E VANTAGEM COMPETITIVA}

Deming (1982) define a qualidade como o nível de satisfação dos clientes, e Juran (1991), por sua vez, descreve a qualidade como sendo a adequação ao uso e a ausência de falhas. Com base nestas definições, pode-se compreender que com a adoção deste modelo de gestão, os estabelecimentos buscam desenvolver melhores condições dos seus produtos/ serviços sempre com foco em atender as necessidades dos clientes.

Neste sentindo Ishikawa (1993, p. 43), destaca que "Qualidade é desenvolver, projetar, produzir e comercializar um produto de qualidade que é mais econômico, mais útil e sempre satisfatório para o consumidor".

Portanto, a gestão da qualidade tem que ser percebida como um processo de melhoria contínua implantado de forma permanente como afirma Paladini (2010, p.314), a gestão da qualidade "não é um esforço temporário, mas algo que se faz sempre, ou seja: a gestão da qualidade é, antes de tudo, uma característica que identifica a organização e, por isso, confunde-se com ela".

É importante compreender que este tipo de gestão é caracterizado por um processo, o qual está em constante mudança adequando-se as necessidades percebidas e que são necessárias adoções de práticas que auxiliem nesse processo.

Dentre estas práticas, Nair (2006) mostra que as mais comuns identificadas na literatura são liderança, gestão de pessoas, planejamento, informação e análise, gestão de processos, gestão de fornecedores, foco em clientes / partes interessadas e design.

Neste sentido, Deming (1982) afirma que inicialmente a aplicação destas práticas de gestão e planejamento nas empresas teve um certo custo e, portanto, gerou um aumento de custos de qualidade implícita. No entanto, este ponto de vista da qualidade mudou progressivamente, e atualmente acredita-se que uma adoção e um compromisso com a melhoria da qualidade podem levar à redução de custos e aumento da produtividade, que permitem que as empresas passem a ganhar quota de mercado, serem reconhecidas e a melhorar a sua competitividade. 
Além disso, Robler Jr e Bonelli (2010) mostram que a gestão da qualidade no processo produtivo das empresas prestadoras de serviços, tem a meta de qualidade operacional baseada no valor percebido pelo cliente, o qual possui uma relação de interdependência com efeito sistêmico dos serviços ofertado.

Portanto, a partir do processo de melhoria dos serviços e da sua prestação que o cliente passa a perceber a diferenciação e assim, a agregar valor ao serviço ofertado e ao empreendimento, no caso meio de hospedagem, uma vantagem competitiva.

Molina-Azorín et al (2015) demostra que a ligação entre a gestão da qualidade, vantagem competitiva e o desempenho, começou a ser analisado e compreendido academicamente apenas na década de 1990 afirmando que a gestão da qualidade gera uma vantagem competitiva.

Por um lado, a gestão da qualidade não gera um melhor desempenho em todas as empresas por pontualidades específicas e que são inerentes a falhas por individualidades da empresa e do método adotado para a implementação, mas gestão da qualidade está relacionada diretamente com estratégias de diferenciação do mercado, não necessariamente a liderança em matéria de custos (PRAJOGO, 2007).

A falta de compromisso e comprometimento gerada por funcionários e gerência é destacado como um problema central no processo de implementação de um programa de gestão da qualidade, uma vez que a relação entre estes atores é interdependente e a falta de comprometimento de um pode acarretar em prejuízo para ambos (MOLINA-AZORÍN et al 2015; AMIN; ALDAKHIL; WU; REZAEI; COBANOGLU, 2017).

Apesar de Parajogo (2007) e Molina-Azorón et al (2015) destacarem esses problemas e falhas individuais que segundo eles, causam comprometimento em todo o processo de implementação da gestão da qualidade, é importante compreender que este tipo de gestão trabalha de forma direta a motivação dos colaboradores para que estes sintam-se parte da empresa e que busquem resultados satisfatórios para atender interesses mútuos.

Por fim, a gestão da qualidade tem sua importância baseada na responsabilidade social da empresa para com os funcionários nela inseridos. No entanto, atualmente as empresas passaram a preocupar-se não apenas com a questão social, mas também com a responsabilidade ambiental e em ser uma empresa sustentável, mantendo o equilíbrio sob as três bases da sustentabilidade, econômica, social e ambiental. A partir disto, algumas delas começaram a 
implantar diferentes tipos de gestão, visando harmonia entre estas variáveis, destacando assim, a gestão ambiental como uma das mais utilizadas e apontadas por estudos que a seguir mostraram a importância desta na diferenciação.

\section{GESTÃO AMBIENTAL E VANTAGEM COMPETITIVA}

A gestão ambiental procura alcançar metas ambientais nas empresas através do planejamento, organização e orientação (NILSON, 1998). Segundo, Nilson (1998, p. 134) a gestão ambiental "pode se tornar também um importante instrumento para as organizações em suas relações com consumidores, o público em geral, companhias de seguro, agências governamentais, etc.”.

É possível compreender a partir desta definição que a gestão ambiental não trata-se apenas de um instrumento que permite a empresa minimizar impactos ambientais, mas também como uma ferramenta importante de auxílio para que o empreendimento possa impactar consumidores, governo e até mesmos os parceiros envolvidos no processo.

Portanto, a partir do que foi exposto anteriormente pode-se entender que as estratégias de gestão são adaptadas para cada tipo de empreendimento de acordo com metas e desejos da empresa, utilizando este tipo de gestão e suas ferramentas disponíveis para alcança-las.

Souza (2002) acrescenta que além de várias outras variáveis (com econômica, social e etc.), atualmente pressões ambientais podem ser impostas e levadas em conta na hora de optar por uma empresa por diversos grupos como acionistas, bancos, investidores, por consumidores e/ou por concorrentes e que por isso, as práticas ambientais têm se tornado menos uma questão ambiental apenas, mas também uma questão de estratégia competitiva.

De acordo com isso, Epelbaum (2004) mostra em seu trabalho a percepção da influência da gestão ambiental em alguns indicadores de sucesso empresarial dentre eles é abordado que a utilização de estratégias de gestão ambiental influencia no crescimento de receita, eficiência operacional e o valor da marca e reputação do empreendimento. Shrivastava (1995) em seu trabalho acrescenta que percebe que a influência da gestão ambiental na vantagem competitiva pode ser analisada através do seu impacto sobre os custos e diferenciação.

No tocante à vantagem competitiva através da diferenciação no mercado, por meio da redução da poluição e impactos negativos, pode ser possível aumentar a demanda por parte dos 
consumidores sensíveis ambientalmente os quais possuem a decisão de compra influenciada por características ambientais de um produto (ELKINGTON, 1994).

Portanto, estes autores tem uma visão comum sobre a diferenciação afetar diretamente o consumidor adepto a este modelo de gestão, que os impactos internos em receita são importantes, mas que o impacto causado ao consumidor é o que garante a empresa um diferencial competitivo.

Além disso, Epelbaum (2004) afirma que empresas com boas iniciativas ambientais podem melhorar a sua reputação ambiental frente ao mercado, dando assim uma ideia de vantagem competitiva. Essa vantagem auxilia de diversas maneiras, uma delas como é mostrada por Molina-Azorín et al (2011), o qual aponta que empresas que adotam estratégias ambientais podem se beneficiar adotando preços mais elevados em relação aos concorrentes justificando uma maior legitimidade no mercado.

É possível observar e compreender que estas empresas perceberam que a adoção de ferramentas de gestão ambiental, causam impactos sobre os custos destas, mas que estes são revertidos e justificados no preço final do produto/serviço.

A este respeito, Jacobs, Singhal e Subramanian (2010) indicam que os anúncios por parte das empresas que adotam este tipo de gestão estão associados a impactos positivos nas ações de mercado da empresa.

No entanto, esta abordagem positiva é contra argumentada com uma abordagem negativa, a qual argumenta que o investimento ambiental pode reduzir a competitividade e desempenho de uma empresa. Deste ponto de vista, sugere-se que o cumprimento da legislação ambiental implica custos elevados, o que prejudica a capacidade da empresa de competir (STAVINS et al., 1995). Portanto, é possível perceber que assim como na gestão da qualidade, há alguns pesquisadores que contra argumentam que a influência da gestão ambiental leva a uma vantagem competitiva.

Portanto, apesar destas diferentes linhas de estudo, este trabalho defende a linha de pensamento que considera a gestão ambiental como uma diferenciação no mercado e por consequência passa a ser considerada uma vantagem. 


\section{ASPECTOS METODOLÓGICOS}

Este estudo se caracteriza como descritivo e relacional, uma vez que se propôs a estabelecer relações entre as estratégias de gestão da qualidade, gestão ambiental e o desempenho competitivo dos hotéis de Pipa- RN. Em relação à abordagem metodológica, este estudo caracteriza-se de natureza qualitativa a qual, "Além dos objetivos amplos da descrição, do desenvolvimento conceitual e do teste de conceitos, a entrevista qualitativa pode desempenhar um papel vital na combinação com outros métodos" (BAUER; GASKELL, 2004, p. 65).

Além disso, tem também um caráter exploratório. Dencker (1998) afirma que, a pesquisa exploratória caracteriza-se por ter em sua composição um levantamento bibliográfico, entrevista com pessoas experientes da área e análise de exemplos similares.

\subsection{População e Amostra}

A população desta pesquisa abrange pousadas localizadas na praia de Pipa/RN, que tiveram avaliações no TripAdvisor. Em virtude dos objetivos da pesquisa, foram selecionadas para compor a amostra as 3 melhores pousadas classificadas pelo usuário no site do TripAdvisor, em um arcabouço amostral de 14 pousadas avaliadas.

A pousada $X$, que teve a maior pontuação com 407 avaliações das quais 349 pontuaram como excelente a estadia no local, foi fundada em 1991 e inicialmente tinham como público principal surfistas e mochileiros que com o passar dos anos teve um remodelamento estrutural e por consequência modificou também o público alvo, atualmente a pousada possui 28 acomodações divididas em Bangalô luxo e Bangalô especial e possui 95 colaboradores ativos no empreendimento.

A pousada Y, que ocupa o segundo lugar no ranking obteve 375 avaliações das quais 305 avaliaram como excelente a estadia no local, foi fundada em 2008 e passou por algumas melhorias na infraestrutura até atualmente. A pousada possui 20 acomodações divididas em Suíte Sênior Vista Jardim, Suíte Sênior Vista Mar e Suíte Master e possui 21 colaboradores ativos no empreendimento.

A pousada Z, que ocupa a terceira colocação obteve 263 avaliações das quais 167 avaliaram a estadia como excelente, foi fundada em 1996 por um italiano, e no primeiro semestre de 2015 foi vendida para a atual gestão, ficando seis meses fechada para realização de 
melhorias na infraestrutura. Atualmente a pousada oferece 9 acomodações divididas em Chalé e Chalé Família e possui 9 colaboradores ativos no empreendimento.

\subsection{Coleta de Dados}

As entrevistas foram aplicadas através de uma pesquisa de campo in loco, com o auxílio de um roteiro voltado aos gestores dos meios de hospedagem onde inicialmente aborda informações gerais sobre os meios de hospedagem e seus respondentes, respectivamente. Tiveram uma duração de cerca de 40 minutos em média e foram gravadas em áudio e posteriormente transcritas literalmente. Os entrevistados assinaram termo de autorização permitindo a gravação e divulgação dos dados coletados. O roteiro utilizado na entrevista foi adaptado do modelo proposto por Molina-Azorín et al (2015).

O roteiro de entrevista é composto por três partes. A primeira parte analisa as estratégias de gestão da qualidade. Nesta parte, é possível investigar quais as ferramentas utilizadas, de que forma são utilizadas, se houve a necessidade de alguma readaptação no modelo, bem como a utilização de quatro indicadores para analisar os impactos que a adoção deste modelo de gestão tiveram em relação aos: custos da empresa, taxa de ocupação, impacto sobre o cliente, qualidade do serviço.

A segunda parte da entrevista investiga as estratégias de gestão ambiental. Sendo possível analisar quais as ferramentas utilizadas, de que forma são utilizadas, se houve a necessidade de alguma readaptação no modelo, bem como a utilização de quatro indicadores para analisar os impactos que a adoção deste modelo de gestão tiveram em relação aos: custos da empresa, taxa de ocupação, impacto sobre o cliente, qualidade do serviço.

Por fim na terceira parte foram analisados pelos gestores a interação entre a gestão da qualidade e a gestão ambiental, a importância de tais modelos e a necessidade de trabalho mútuo entre ambos.

\subsection{Análise de Dados}

Os dados coletados por meio das entrevistas foram categorizados e subdivididos de acordo com os objetivos propostos pelo trabalho buscando investiga-los, por isso, a análise ficou dividida em três categorias que foram: Análise do gerenciamento da qualidade nas pousadas; Análise do gerenciamento ambiental nas pousadas e Diagnóstico da relação dos dois tipos de gestão nas pousadas. 
Inicialmente, na categoria de gestão da qualidade foi possível analisar se a pousada adotava este modelo de gestão bem como se havia a adoção de práticas ou ferramentas no processo de gerenciamento, se foram necessárias adaptações às medidas implantadas e os impactos deste modelo adotado tanto internamente nos custos da empresa quanto externamente na percepção do cliente.

Posteriormente, na categoria de gestão ambiental foi possível analisar se a pousada adotava também este modelo de gestão bem como se havia a adoção de práticas ou ferramentas no processo de gerenciamento, se foram necessárias adaptações às medidas implantadas e os impactos deste modelo adotado tanto internamente nos custos da empresa quanto externamente na percepção do cliente.

E por fim, foi possível através da visão dos gerentes analisar se havia relação entre estes dois tipos de gestão, se era viável trabalha-las de forma isolada, se uma gestão tinha dependência ou influência direta sobre a outra.

Abaixo segue o Quadro 1 com a amarração metodológica o qual facilita a compreensão do que acima foi exposto, além disso, nele está contido as perguntas que auxiliaram no direcionamento da entrevista para obter as informações acima citadas.

Quadro 1: Quadro de amarração metodológica do estudo

\begin{tabular}{|c|c|c|}
\hline $\begin{array}{c}\text { Objetivos específicos } \\
\text { do trabalho }\end{array}$ & Categorias de análises & Questões do roteiro de entrevistas \\
\hline \multirow{7}{*}{$\begin{array}{l}\text { Investigar a gestão da } \\
\text { qualidade nas pousadas; }\end{array}$} & -Definição & P1 - Para você, o que é gestão da qualidade? \\
\hline & -Adoção das práticas/ ferramentas & $\begin{array}{l}\text { P2- A pousada possui ferramentas de gestão da } \\
\text { qualidade? Quais? É importante possuir essas } \\
\text { ferramentas? Por quê? O que levou a pousada a } \\
\text { adotar práticas de gestão da qualidade? }\end{array}$ \\
\hline & -Necessidades de adaptações & $\begin{array}{l}\text { P3-Há quanto tempo o empreendimento adota } \\
\text { essas ferramentas? Depois da adoção, já foi } \\
\text { necessária readaptação? Por quê? Quais impactos a } \\
\text { gestão da qualidade gera sobre os custos da } \\
\text { empresa? }\end{array}$ \\
\hline & \multirow{3}{*}{$\begin{array}{l}\text {-Resultados alcançados com as } \\
\text { práticas }\end{array}$} & $\begin{array}{l}\text { 4-A gestão da qualidade proporciona um } \\
\text { diferencial competitivo para a pousada? Por quê? }\end{array}$ \\
\hline & & $\begin{array}{l}\text { P5-Houve alguma diferença em termos de taxa de } \\
\text { ocupação percebida após a adoção do modelo de } \\
\text { gestão? De que forma? }\end{array}$ \\
\hline & & $\begin{array}{l}\text { P6-Qual o impacto percebido diretamente e } \\
\text { indiretamente sobre o cliente na adoção deste } \\
\text { modelo de gestão? }\end{array}$ \\
\hline & $\begin{array}{l}\text {-Influências positivas e negativas } \\
\text { no produto }\end{array}$ & $\begin{array}{l}\text { P7- A adoção de práticas de gestão da qualidade } \\
\text { influencia no valor do produto ou serviço? Esse } \\
\text { impacto é positivo ou negativo? Por quê? }\end{array}$ \\
\hline
\end{tabular}




\begin{tabular}{|c|c|c|}
\hline \multirow{7}{*}{$\begin{array}{l}\text { Verificar a gestão } \\
\text { ambiental nas } \\
\text { pousadas; }\end{array}$} & -Definição & P8 - Para você, o que é gestão ambiental? \\
\hline & -Adoção das práticas/ ferramentas & $\begin{array}{l}\text { P9- A pousada possui ferramentas de gestão } \\
\text { ambiental? É importante adotar tal modelo de } \\
\text { gestão? Por quê? O que levou a pousada a adotar } \\
\text { práticas de gestão ambiental? }\end{array}$ \\
\hline & -Necessidades de adaptações & $\begin{array}{l}\text { P10-Há quanto tempo o empreendimento adota } \\
\text { essas ferramentas? Depois da adoção, já foi } \\
\text { necessária readaptação? Por quê? Quais impactos a } \\
\text { gestão ambiental gera sobre os custos da empresa? }\end{array}$ \\
\hline & $\begin{array}{l}\text {-Resultados alcançados com as } \\
\text { práticas }\end{array}$ & $\begin{array}{l}\text { P11-Houve alguma diferença em termos de taxa de } \\
\text { ocupação percebida após a adoção do modelo de } \\
\text { gestão? De que forma? }\end{array}$ \\
\hline & \multirow{3}{*}{$\begin{array}{l}\text {-Influências positivas e negativas } \\
\text { no produto }\end{array}$} & $\begin{array}{l}\text { P12- A gestão ambiental influencia na vantagem } \\
\text { competitiva? De que forma? }\end{array}$ \\
\hline & & $\begin{array}{l}\text { P13- Este modelo de gestão ambiental impacta na } \\
\text { qualidade e preço do serviço ou produto? Esse } \\
\text { impacto é positivo ou negativo? Por quê? }\end{array}$ \\
\hline & & $\begin{array}{l}\text { P14-Qual o impacto percebido diretamente e } \\
\text { indiretamente sobre o cliente na adoção deste } \\
\text { modelo de gestão? Exemplifique. }\end{array}$ \\
\hline \multirow{2}{*}{$\begin{array}{l}\text { Diagnosticar a relação } \\
\text { existente entre a gestão } \\
\text { ambiental e a gestão da } \\
\text { qualidade; }\end{array}$} & \multirow{2}{*}{$\begin{array}{l}\text {-Relações entre gestão da qualidade } \\
\text { e gestão ambiental }\end{array}$} & $\begin{array}{l}\text { P15- Você percebe alguma relação prática entre a } \\
\text { gestão da qualidade e a gestão ambiental? Qual? } \\
\text { Explique. }\end{array}$ \\
\hline & & $\begin{array}{l}\text { P16- Em sua opinião, é possível trabalhar com } \\
\text { estes dois tipos de gestão de maneira isolada? }\end{array}$ \\
\hline
\end{tabular}

Fonte: Autores (2018)

\section{ANÁLISE DA GESTÃO DA QUALIDADE}

\subsection{Pousada X}

A pousada $X$, possui uma gestão da qualidade madura, a qual começou a ser implementada no empreendimento desde sua fundação e passou por ajustes ao longo de sua trajetória. O gerente entrevistado caracterizou a gestão da qualidade não apenas como um tipo de gestão social, mas também ambiental, envolvendo os colaboradores e o ambiente em que eles trabalham.

Como ferramentas de gestão utilizadas pela empresa foram citadas a priorização da mão de obra local, investindo em capacitação destes colaboradores, que segundo o gerente, é fundamental para o empreendimento expressando-se assim: “A gente tenta captar mão de obra local e regional, preferencialmente inexperiente, para moldar e lapidar de acordo com as políticas do empreendimento que são bem específicas voltadas para o meio ambiente e responsabilidade social". 
Além disso, o estabelecimento investe em motivação salarial para os funcionários uma vez que foi citado que é importante manter os colaboradores motivados, pois segundo o gestor: "O objetivo da empresa é que cada funcionário seja um formador e reprodutor dos conceitos aqui pregados" mostrando a preocupação em minimizar os problemas apontados por Prajogo (2007), o qual aponta que problemas pontuais resultam em colaboradores desmotivados que podem interferir na qualidade do produto final ofertado.

O empreendimento preocupa-se na formação de parcerias que possuam as mesmas ideologias para que não ocorra como acima citado, interferência no produto final. Também é adotado opinário como ferramenta de gestão, no check out para que os clientes possam manifestar opiniões, queixas, insatisfações e elogios, sendo estes atendidos quando possível.

Ademais, são realizadas auditorias internas e externas onde avaliadores incógnitos se hospedam no empreendimento a fim de avaliar os serviços prestados. Como estas auditorias externas ocorrem sem breve aviso, a pousada possui auditorias internas para analisar pontos críticos e melhora-los utilizando como auxilio para isso, opinião dos hospedes, por isso, além do opinário a empresa leva em consideração comentários do Booking e Tripadvisor.

Quando questionado a respeito dos impactos nos custos para adoção deste tipo de gestão foi mostrado que os impactos na capacitação não são altos comparados ao retorno que é obtido com a qualificação profissional, mostrando pensamento semelhante ao de Molina-Azorín et al (2015) o qual em seu trabalho aponta que a qualificação melhora a forma de como o hotel é gerido, o que leva à melhoria da satisfação do cliente, qualidade do serviço e imagem do hotel.

Além disso, com a adoção desta gestão foi percebido redução das reclamações dos clientes, aumento da satisfação do cliente (mensurada pelos opinários), menores erros de serviço uma vez que há capacitação profissional, e foi dito pelo gestor que por trabalhar a motivação há baixo absenteísmo por parte dos funcionários, aumento da satisfação do empregado que segundo ele é avaliada pelos gestores e estes fatores, impactam na qualidade do serviço. O mesmo foi mostrado no trabalho de Molina-Azorín et al (2015), onde os empreendimentos hoteleiros na Espanha mostraram que a gestão da qualidade influencia positivamente nestes fatores acima citados.

Quando perguntado sobre os impactos da adoção deste modelo de gestão sobre a taxa de ocupação, o gestor afirmou que a taxa de ocupação aumentou, mas a mudança mais significativa foi o perfil dos usuários que passou a ter em sua composição não apenas clientes 
mais críticos e exigentes, mas que optam por pousadas que possuam esta gestão. O gestor afirmou que é importante readaptar estratégias porque segundo ele: “o segredo do sucesso é nunca se acomodar, buscar sempre se superar, melhorar, inovar”

\subsection{Pousada Y}

A pousada $\mathrm{Y}$ está em processo de implantação da gestão da qualidade, visto que a gerente entrevistada se mostrou interessada em melhorar o desempenho do empreendimento e ciente da importância da adoção deste modelo de gestão. Quando questionada sobre o que é gestão da qualidade ela definiu como uma gestão que busca atender as expectativas e necessidades do cliente, mas buscando sempre balancear preço e qualidade, pensamento semelhante ao de Ishikawa (1993) o qual define que qualidade é produzir e oferecer um produto de qualidade, no entanto que seja econômico, útil e sempre satisfatório para o consumidor.

Apesar de estar em processo de implantação, a pousada já possui ferramentas sendo utilizadas como: curso de formação estão sendo ofertados aos funcionários, a pousada também possui sistema de bonificação para o colaborador, onde estes recebem parte do lucro obtido pela empresa, buscando assim motiva-los. Além disso, a pousada possui parceria com empresas terceirizadas aumentando o número de serviços ofertados ao hóspede.

Ademais, o empreendimento faz auditorias internas buscando assim como na pousada $\mathrm{X}$ minimizar erros e falhas, e percebem que estas são fundamentais e impactantes na satisfação do cliente (é mensurada através das avaliações feitas no check out). Além disso, o estabelecimento analisa as críticas e sugestões feitas no TripAdvisor e quando possível entende-as. Com esta adoção, mesmo que inicial já foi percebido redução das reclamações dos clientes, menores erros de serviços, menor número de queixa dos funcionários e aumento de produtividade. Como o empreendimento ainda está em fase de implementação ainda não foram necessárias readaptações, no entanto, quando questionada a respeito do impacto da adoção deste modelo nos custos da empresa, ela respondeu: " o impacto é mínimo pelo retorno que a empresa ganha" e acrescentou "quando se investe em um funcionário por exemplo: um curso de confeitaria para o cozinheiro: ele aprende a fazer melhores tortas o que é refletido no buffet que a empresa oferece formando uma reação em cadeia pois você investe em um setor e você ganha em satisfação do hóspede, avaliação e até mesmo divulgação" 
Assim como na pousada $\mathrm{X}$, a pousada $\mathrm{Y}$ percebeu que com a adoção deste tipo de gestão não houve apenas uma mudança na taxa de ocupação, mas uma mudança no perfil do consumidor e que segundo ela, o mercado mostra esta tendência por clientes que pagam a mais, mas que exigem serviços de excelência.

\subsection{Pousada $Z$}

A pousada $\mathrm{Z}$ não possui gestão da qualidade. Por ter sido adquirida recentemente pela nova gestão, a gestora afirma que não conseguiu implantar este modelo, mas reconhece ser importante a implementação e define esta como: "gestão da qualidade é a relação entre o serviço que oferece e um bom preço". No entanto, apesar de não ter sido imposta, algumas ferramentas estão sendo introduzidas como: análise dos comentários e críticas gerados pelo usuário no TripAdvisor, possuem parceria com empresas terceirizadas ofertando diferentes serviços, e a atual gestão readmitiu os funcionários da antiga gestão e contratou alguns novos (possibilitando a troca de experiências pois a antiga gestão possuía manuais os quais auxiliaram no treinamento dos novos colaboradores).

Portanto, apesar de ainda estar em fase inicial, a gestora da pousada reconhece a importância da implementação da gestão da qualidade e assim como a pousada $Y$ afirma que "se você investe no funcionário ele reflete o aprendizado na pousada, aumentando a satisfação do cliente".

\section{ANÁLISE DA GESTÃO AMBIENTAL}

\subsection{Pousada X}

Assim como a gestão da qualidade pousada $\mathrm{X}$ possui uma gestão ambiental sólida, a qual começou a ser implementada no empreendimento desde sua fundação e passou por ajustes concomitantes a outras gestões ao longo dos anos. O gerente entrevistado caracterizou a gestão ambiental como uma gestão que integra a preservação do meio ambiente e os recursos naturais visando o futuro do empreendimento e do ambiente em que ele se encontra.

Como ferramentas de gestão utilizadas pela empresa foram citadas a avaliação do registro ambiental dos fornecedores, eles preparam relatórios ambientais com as atividades desenvolvidas durante o ano, possuem indicadores financeiros e operacionais os quais são usados para medir o impacto ambiental e os seus custos na receita da empresa. Estes medem os impactos na receita em investimentos de médio e longo prazo, como a implementação de placas 
solares, utilização de sensores de movimentos que segundo o gestor foi um investimento alto, mas que está tendo retorno. Existe também a avaliação dos resultados obtidos relacionados a redução do impacto ambiental através da utilização de produtos de baixo impacto ambiental, e compostagem feita com os resíduos do restaurante da pousada.

Além disso, foi citado que recursos são fornecidos, a fim de realizar melhorias ambientais no estabelecimento como exemplo, o gerente citou a construção de um lago artificial no meio da pousada para abrigar espécies que devido a urbanização da cidade buscaram refúgio na pousada.

Ademais, foi informado que a empresa adota produtos de baixo impacto ambiental, produtos de limpeza biodegradáveis para minimizar o impacto destes no empreendimento. Há também eliminação / tratamento / armazenamento adequado dos resíduos, uma das práticas citada como exemplo foi a da compostagem, a pousada reutiliza os restos de alimentos advindos do restaurante, fazem tratamento destes restos e utilizam para adubar as plantas nativas do local.

Além destas práticas, a pousada também implementa medidas a fim de reduzir o consumo de água e de energia, o empreendimento possui sensores de presença que são utilizados nos corredores a noite para acenderem as luzes apenas na presença de hóspedes. Também possuem placas solares de energia, onde parte da energia utilizada no estabelecimento advém delas, fazem uso do "cartão inteligente" que para sair do quarto o cliente precisa dele e ao retira-lo do local a energia é cessada em minutos, e possuem descargas com controle de fluxo.

Quando questionado a respeito da gestão ambiental como uma vantagem competitiva o gestor afirma que o futuro da rede hoteleira é investir em gestão ambiental projetando um futuro sustentável. E acrescentou que a utilização deste tipo de gestão tem impacto positivo tanto em questões econômicas como- redução no consumo de água, redução no consumo de energia, redução de resíduos sólidos, redução das descargas, redução do barulho e menores danos as paisagens- quanto social, em como a pousada é vista pelos usuários, reforçando a ideia de Epelbaum (2004) o qual afirma que as empresas que possuem iniciativas ambientais podem melhorar a sua reputação ambiental frente ao mercado, proporcionando assim uma vantagem competitiva. O gerente completa mostrando que a reputação não é reconhecida apenas pelo 
mercado mas também pelos funcionários que segundo ele "vestem a camisa da empresa e acabam sendo reprodutores destas ideias em casa e na comunidade".

\subsection{Pousada Y}

A pousada Y, não possui gestão ambiental implantada no empreendimento, no entanto ela adota algumas ferramentas durante sua gestão. Quando questionada sobre o que é gestão ambiental, a gerente definiu como uma gestão que busca trabalhar de forma sustentável atendendo questões ecológicas, econômicas e sociais.

Dentre as ferramentas adotadas pelo estabelecimento estão: avaliam o registro ambiental dos fornecedores, em especial empresas de dedetização, possuem descargas com controle de fluxo, fazem a utilização do "cartão inteligente" e patrocinam o santuário ecológico de Pipa (uma reserva florestal).

Quando questionada a respeito da gestão ambiental como uma vantagem competitiva a gestora afirma que não reconhece a adoção deste tipo de gestão como uma vantagem e acrescenta “90\% dos hóspedes que acolhemos não nos escolhem pelas questões ambientais".

Por fim, o impacto positivo percebido e relatado na adoção de algumas destas ferramentas foi a diminuição de gastos e consequente aumento da receita e por este motivo foi afirmado que a partir disto pode se ter uma vantagem competitiva, oferecendo serviço de qualidade por menor preço, validando o que foi dito por Shrivastava (1995) em seu trabalho o qual percebe que a influência da gestão ambiental na vantagem competitiva pode ser analisada através do seu impacto sobre os custos.

\subsection{Pousada Z}

Assim como a gestão da qualidade, a pousada Z, não possui gestão ambiental. E segundo a gestora algumas poucas ferramentas que atualmente são utilizadas foram implementadas por questões econômicas e não ambientas, as ferramentas adotadas são: uso do "cartão inteligente" e uso de descargas com controle de fluxo.

Apesar de reconhecer que é importante, o uso de uma gestão ambiental e o uso de algumas ferramentas auxiliam na economia e no aumento da receita, a gestora destaca que “ainda estamos nos adaptando ao local e público, iniciamos as atividades a mais ou menos um ano e para implantar este tipo de gestão é preciso que a pousada já esteja estável”. 


\section{RELAÇÃO ENTRE GESTÃO DA QUALIDADE, GESTÃO AMBIENTAL E COMPETITIVIDADE}

Quando perguntados se observavam alguma relação entre gestão ambiental e gestão da qualidade e se ambas podem ser trabalhadas de maneira isolada, o gerente da pousada $\mathrm{X}$ respondeu que ambas andam em conjunto e se complementam explicando que um hotel que possui gestão ambiental ele não oferece apenas um serviço de excelência com qualidade, mas também que esta gestão impacta o usuário e funcionário e algumas vezes estes adotam e são reprodutores destas ideologias em casa e na comunidade que habitam.

No entanto, a gestora da pousada Y acredita que existe uma relação de complemento entre os dois tipos de gestão, mas defende que ambas podem ser trabalhadas de maneira isolada e mesmo assim cumprirem com seus objetivos. Acrescentando que existem públicos diversos e que estes possuem interesses diferentes, sendo possível adotar apenas um destes modelos e concomitantemente atender as necessidades de um destes segmentos.

Já a gestora da pousada Z, apesar de não adotar nenhuma das duas gestões, concorda com o gestor da pousada $X$ e acredita que ambas gestões se complementam e que estas possuem impactos diretos e indiretos na percepção de valor pelo cliente. Além disto, adotandoas permite a pousada possuir funcionários satisfeitos e ainda ter ao mesmo tempo vantagem sobre os custos uma vez que algumas das ferramentas destas gestões além dos benefícios acima citados, agregam ao empreendimento aumento na receita (segundo ela, objetivo principal dos empreendimentos).

A partir dos questionamentos e opiniões anteriormente citadas, foi feita uma tabela (a seguir) que contém o grau satisfação dos clientes a partir de suas avaliações pelo TripAdvisor.

Tabela 1: Avaliação dos usuários através do TripAdvisor sobre pousadas do estudo em Pipa/RN, em 2016.

\begin{tabular}{l|c|c|c}
\multicolumn{1}{c|}{ Classificações } & Pousada X & Pousada Y & Pousada Z \\
\hline Excelente & 351 & 306 & 167 \\
\hline Muito bom & 45 & 65 & 78 \\
\hline Razoável & 5 & 3 & 2 \\
\hline Ruim & 2 & 1 & 1 \\
\hline Horrível Total & 4 & 0 & $\mathbf{2 6 3}$ \\
\hline \multicolumn{2}{c|}{}
\end{tabular}

Fonte: TripAdvisor (2016)

Acima pode-se perceber que a pousada mais bem avaliada foi a pousada $\mathrm{X}$, a qual teve aproximadamente sessenta por cento das avaliações como excelente, em segundo veio a 
pousada Y com aproximadamente cinquenta por cento das avaliações classificada como excelente e a pousada $\mathrm{Z}$ teve aproximadamente quarenta por cento das avalições de forma excelente.

A partir da análise destes dados pode-se associar à pousada que adota ambos os tipos de gestão com um melhor desempenho quando comparado as demais. É importante observar que a pousada $\mathrm{X}$ adota os dois tipos de gestão, e estes estão implementados na empresa há muito tempo, sendo possível perceber um diálogo entre o que foi apresentado numericamente acima com o que Molina-Azorín et al (2015) apresentaram em seu trabalho que quanto mais avançado o grau de implementação das práticas de gestão da qualidade, maior é a possibilidade de melhorar a satisfação do cliente, reduzir erros na prestação de serviços, aumentar a qualidade do serviço oferecido e melhorar a satisfação dos colaboradores.

Além disto é possível dialogar entre os resultados obtidos na análise da gestão da qualidade onde o gestor da pousada $X$ afirma que a pousada em questão com a adoção deste tipo de gestão permite ao empreendimento uma diferenciação quanto a imagem formada pelo consumidor a respeito do estabelecimento e o mesmo foi encontrado no trabalho de MolinaAzorín et al (2015), o qual mostra que a gestão da qualidade impacta na diferenciação hoteleira, em especial na imagem de forma positiva e além disso, na inovação dos serviços prestados em relação ao concorrente.

No entanto, a pousada Y que ocupa a segunda colocação, adota apenas um tipo de gestão e algumas ferramentas de outra, e a terceira pousada $Z$ não possui nenhum tipo de gestão, adotando apenas algumas ferramentas.

A partir deste resultado, é possível confirmar o que Molina-Azorín et al (2015) demostram em seu estudo feito na Espanha o qual afirma que a gestão da qualidade; e as práticas de gestão ambiental permitem que os hotéis melhorem seu desempenho ambiental, reduzindo os impactos ambientais e que este melhor desempenho ambiental contribui para um maior desenvolvimento da diferenciação, na medida em que pode ajudar a melhorar a imagem do hotel e reduzir o uso de energia, água e recursos, bem como reduzir outros custos operacionais que são importantes para hotéis.

Podendo ainda, ser percebido através da comparação entre este estudo e o de MolinaAzorín et al (2011) que a gestão ambiental pode se tornar um fator de diferenciação, pois há poucos hotéis aplicando técnicas avançadas de gestão ambiental -com sistemas técnicos e 
estratégicos os quais são importantes para criar esses efeitos positivos- o que foi possível ser constatado nesta pesquisa que apenas uma das pousadas faz o uso desta gestão, fazendo com que seja a gestão ambiental o diferencial competitivo.

Portanto, pode-se compreender que a adoção da gestão ambiental e da gestão da qualidade de forma conjunta impactam positivamente a experiência do cliente, sendo demostrado este impacto através das avaliações emitidas por eles no site. Não significando que a adoção apenas de uma das gestões não impacte positivamente, mas o resultado da interação das gestões foi mais positivo e evidenciado.

\section{CONSIDERAÇÕES FINAIS}

Diante dos resultados alcançados no estudo, quanto às relações entre gestão da qualidade e gestão ambiental relacionadas ao desempenho na competitividade na hotelaria de Pipa-RN, pôde-se chegar às seguintes conclusões. No que se refere à influência das estratégias de gestão da qualidade como diferencial competitivo para o empreendimento, foi confirmado o que foi mostrado por Robler Jr e Bonelli (2010) que gestão da qualidade no processo produtivo das empresas prestadoras de serviços é baseada no valor percebido pelo cliente, e este possui uma relação de interdependência com efeito sistêmico dos serviços ofertados.

No entanto, estas influências da adoção deste modelo como diferencial são mais perceptíveis em empreendimentos com uma gestão consolidada como apresentado no estudo, onde se é possível melhorar a satisfação do cliente, reduzir erros na prestação de serviços, aumentar a qualidade do serviço oferecido e melhorar a satisfação dos colaboradores.

Além disso foi possível dialogar e confirmar os resultados obtidos por Molina-Azorín et al (2015) que demostrou que ambos os tipos de gestão são fundamentais na competitividade do empreendimento, mas que a gestão ambiental por ser de maneira geral menos adotada, passa a ser mais importante para a empresa que busca se diferenciar e por consequência ser mais competitiva.

Diante do exposto, acredita-se que o estudo conseguiu ampliar a compreensão sobre as relações entre as gestões ambiental e da qualidade associando-as a competitividade, ressaltando a importância da adoção de ambas de forma concomitante e harmônica. Desse modo, os resultados apresentados comprovaram que melhorias gerais no desempenho dos empreendimentos relacionados a competitividade são possíveis a partir de um conjunto de 
práticas de gestão da qualidade aliada a gestão ambiental, trabalhadas de forma simultânea na prestação do serviço.

As limitações percebidas baseiam-se em que este estudo permite apena induzir as relações comentadas acima, mas não é possível afirmar que o hotel X é melhor avaliado porque adota a gestão da qualidade e a gestão ambiental, sendo possível que outros fatores que não foram investigados no estudo também interferem na competitividade dos empreendimentos. Além disso, a carência de estudos anteriores que apontem resultados significativos para serem debatidos e comparados foi outro fator limitante e por fim, a aceitação por parte dos gestores em participarem da pesquisa tornou-se um fator de relevância no decorrer da elaboração do trabalho.

Como sugestões para futuras pesquisas complementares, recomenda-se a condução de estudos similares em outras regiões geográficas do país, bem como em outros países, com características culturais distintas, para permitir comparações e identificar possíveis diferenças. Também se propõe o desenvolvimento de estudos quantitativos para verificação do número de empreendimentos que adotam estas gestões para que possam dialogar com os resultados obtidos qualitativamente.

Recomenda-se, ainda, que futuras pesquisas testem a inserção de outros tipos de gestão na análise da competitividade, com o intuito de identificar fatores que possam, complementarmente às capacidades organizacionais, contribuir para a explicação da variação de desempenho das organizações.

\section{REFERÊNCIAS}

AMIN, Muslim; ALDAKHIL, Abdullah Mohamed; WU, Chengzhong; REZAEI, Sajad; COBANOGLU, Cihan. The structural relationship between TQM, employee satisfaction and hotel performance. International Journal of Contemporary Hospitality Management, Vol. 29 Issue: 4, pp.1256-1278, 2017. https://doi.org/10.1108/IJCHM-11-2015-0659

BAUER, Martin W; GASKELL, George. Pesquisa Qualitativa com Texto, Imagem e Som: um manual prático. 3. ed. Rio de Janeiro: Vozes, 2004.

CARPINETTE, Luiz Cesar Ribeiro. Gestão da qualidade: conceitos e técnicas. São Paulo: Atlas, 2010

DEMING, W. Edwards. Qualidade: a revolução da administração. Rio de Janeiro: Marques Saraiva, 1982. 
DENCKER, Ada de Freitas Maneti. Pesquisa em turismo: planejamento, métodos e técnicas. São Paulo: Futura, 1998.

ELKINGTON, John. Towards the sustainable corporation: winewin business strategies for sustainable development. California Management Review, v. 36, n.2, p. 90-100, 1994.

EPELBAUM, Michel. A influência da gestão ambiental na competitividade e no sucesso empresarial. Dissertação (Mestrado Engenharia de Produção) - Escola Politécnica, Universidade de São Paulo, 2004. Disponível em: $<$ http://www.teses.usp.br/teses/disponiveis/3/3136/tde-02072004-190334/es.php>. Acesso em: 3 maio. 2016.

IBGE. Pesquisa de Serviços de hospedagem. Diretoria de Pesquisas, Coordenação de Serviços e Comércio. 2011.

ISHIKAWA, Kaoru. Controle de qualidade total à maneira japonesa. 6 ed. Rio de Janeiro: Campus, 1993.

JACOBS, B.W., SINGHAL, V. R., SUBRAMANIAN, R. An empirical investigation of environmental performance and the market value of the firm. Journal of Operations Management, v. 28, n. 5, p. 430- 441, 2010.

MOLINA-AZORÍN, Jose. F, et al. Environmental perception, management, and competitive opportunity in Spanish hotels. Cornell Hospitality Quarterly, v. 52, n. 4, p. 480-500, 2011.

MOLINA-AZORÍN, Jose. F, et al. The effects of quality and environmental management on competitive advantage: a mixed methods study in the hotel industry. Tourism Management, v. 50, p. 41-54, October, 2015.

NAIR, Anand. Meta-analysis of the relationship between quality management practices and firm performance-implications for quality management theory development. Journal of Operations Management, v. 24, n. 6, p. 948-975, 2006.

NILSON, W. R. Services instead of products: experiences from energy markets examples from Sweden. In: MEYER-KRAHMER, F. (Ed.). Innovation and sustainable development: lessons for innovation policies. Heidelberg: Physica-Verlag, 1998.

PALADANI, Edson Pacheco. Gestão da qualidade: teoria e prática. 2.ed. 9 reimpr. São Paulo: Atlas, 2010.

PÉREZ, Marta Arbelo; ARBELO, Antonio; GÓMEZ, Pilar Pérez. Impact of quality on estimations of hotel efficiency. Tourism Management. v 61, p. 200-208, 2017. http://dx.doi.org/10.1016/j.tourman.2017.02.011

PRAJOGO, Daniel. I. The relationship between competitive strategies and product quality. Industrial Management \& Data System, v. 107, n. 1, p.69 - 83. 2007.

ROBLES JR, Antonio; BONELLI, Valério Vitor. Gestão da qualidade e do meio ambiente: enfoque econômico, financeiro e patrimonial. 1.ed. 3. reimpr. São Paulo: Atlas, 2010.

SHRIVASTAVA, Paul. The role of corporations in achieving ecological sustainability. Academy of Management Review, v.20, n. 4, p. 936-960, 1995. 
PEREIRA, Priscilla Correia, BARRETO, Leilianne M. T. Silva, LIMBERGER, Pablo Flôres, MENDES FILHO, Luiz. OS EFEITOS DA GESTÃO DA QUALIDADE E DA GESTÃO AMBIENTAL (...). Revista Hospitalidade. São Paulo, volume 15, n.01, p. 27-49, jan-jul de 2018. DOI: https://doi.org/10.21714/2179-9164.2018v15n1.797

SOUZA, Renato. S. Evolução e condicionantes da gestão ambiental nas empresas. REAd. Santa Maria. Edição Especial 30 Vol. 8 No. 6, 2002.

STAVINS, Robert. N, et al,. Environmental regulation and the competitiveness of U.S. manufacturing: what does the evidence tell us. Journal of Economic Literature, v.33, n. 1, p. 132-163, 1995.

VIDAL, Soraia M. S. C. Dunas, lagoas e praias - Turismo e Sustentabilidade em Natal - RN. Revista Ponto e Vírgula, v.7, p. 77-94, 2010.

Artigo recebido em: 27/02/2018

Avaliado em: 16/05/2018

Aprovado em: 17/05/2018 